\title{
Nurmipalkokasvien jälkivaikutus maan mineraalityppivaroihin ja viljan satoon
}

\author{
Mika Isolahti ${ }^{1)}$, Arto Huuskonen ${ }^{1)}$, Mikko Tuori ${ }^{2)}$ ja Oiva Nissinen ${ }^{3)}$ \\ 1)MTT,Pohjois-Pohjanmaan tutkimusasema,92400Ruukki,etunimi.sukunimi@mtt.fi \\ 2) Helsingin yliopisto, Kotieläintieteenlaitos,00014 Helsingin yliopisto, mikko.tuori@helsinki.fi \\ ${ }^{3)}$ MTT, Lapin tutkimusasema, Tutkijantie 28,96900 Saarenkylä, oiva.nissinen@mtt.fi
}

\begin{abstract}
Johdanto
Nurmipalkokasvien viljely on usein esitetty mahdollisuus typen hyväksikäytön parantamiseksi kotieläintuotannossa. Aiemmin kiinnostusta nurmipalkokasvien viljelyyn on hillinnyt mm. typpiväkilannoitteiden halpa hinta, vaikeudet nurmipalkokasvisäilörehun valmistuksessa ja nurmipalkokasvien suhteellisen huono talvenkestävyys sekä alttius kasvitaudeille ja tuhoeläimille. Ongelmien osittainen ratkaiseminen kasvinjalostuksen avulla sekä lisääntyvä huoli ympäristön tilasta ovat johtaneet siihen, että nurmipalkokasvien viljelyä on alettu jälleen pitää varteenotettavana vaihtoehtona korkeasti väkilannoitetuille heinäkasvinurmille. Aiemmissa tutkimuksissa on kuitenkin saatu viitteitä tapauksista, joissa sinimailasen (Robbins ja Carter 1980, Bergström 1986) ja valkoapilan (Low 1973, Adams ja Pattison 1985) viljelyn yhteydessä maaperään on kertynyt niin suuria määriä typpeä, etteivät kasvit ole pystyneet sitä hyväksikäyttämään. Tällaisissa tapauksissa nitraatin huuhtoutumisriski on erittäin suuri.

Euroopan Unionista rahoitusta saaneessa LEGSIL -projektissa (Low input animal production based on forage legume for silage, FAIR CT 96 - 1832) tutkittiin nurmipalkokasvisäilörehuihin perustuvan kotieläintuotannon mahdollisuuksia pohjoisessa Euroopassa. Projektin yhtenä tavoitteena oli tutkia nurmipalkokasvituotannon vaikutuksia maaperän mineraalityppivaroihin.
\end{abstract}

\begin{abstract}
Aineisto ja menetelmät
Nurmipalkokasvien vaikutusta maaperän mineraalityppivaroihin tutkittiin Suomessa kolmella eri paikkakunnalla: Viikin opetus- ja tutkimustilalla Helsingissä sekä MTT:n Pohjois-Pohjanmaan tutkimusasemalla Ruukissa ja Lapin tutkimusasemalla Rovaniemellä. Tutkittavat palkokasvilajit ja lajikkeet olivat puna-apila (Vivi ja Björn), valkoapila (Aberherald ja Jögeva), sinimailanen (Vertus ja Lesina), rehuvuohenherne (Gale) ja keltamaite (Leo). Palkokasveja kylvettiin sekä puhtaana kasvustona että seoksena nurminadan (Kasper ja Salten) kanssa. Lisäksi vertailussa oli mukana nurminata (Kasper) puhtaana kasvustona joko ilman typpilannoitusta tai $200 \mathrm{~kg} \mathrm{ha}^{-1}$ typpilannoituksen saaneena.

Kylvökesänä kasvustot saivat starttilannoituksena $40-50 \mathrm{~kg} \mathrm{~N} \mathrm{ha}{ }^{-1}$. Fosfori- ja kaliumlannoitukset suoritettiin ympäristötukiehtojen mukaisesti. Perustamisvuoden jälkeisinä vuosina palkokasviruuduille suoritettiin ainoastaan P- ja K-lannoitus maaperän ravinnekoostumuksen mukaan. Vertailussa mukana olleelle väkilannoitetulle nurminadalle annettiin lisäksi väkilannoitetyppeä $200 \mathrm{~kg} \mathrm{ha}^{-1}$, josta $100 \mathrm{~kg}: a$ keväällä ja loput ensimmäisen niiton jälkeen myöhemmin kesällä. Ruukissa typpilannoituksena käytettiin typpiväkilannoitteen sijaan naudan virtsaa.

Kolmannen satovuoden jälkeen kasvustot lopetettiin glyfosaattiruiskutuksella, ja maanäytteet otettiin kokeen päättymisen jälkeisenä syksynä ja seuraavana keväänä roudan sulamisen jälkeen. Näytteiden otto tapahtui kolmesta eri syvyydestä: $0-33 \mathrm{~cm}, 33-66 \mathrm{~cm}$ ja $66-100 \mathrm{~cm}$. Rovaniemellä pystyttiin maaperän kivisyydestä johtuen ottamaan maanäytteet vain kahdesta ylimmästä kerroksesta. Maanäytteistä määritettiin sekä nitraattityppi- $\left(\mathrm{NO}_{3}-\mathrm{N}\right)$ että ammoniumtyppipitoisuus $\left(\mathrm{NH}_{4+} \mathrm{N}\right)$, jotka yhteenlaskettuna kertovat maaperän mineraalityppipitoisuuden. Lisäksi arvioitiin eri nurmipalkokasvien esikasviarvo seuraavana vuonna viljellyn kauran tai vehnän satojen perusteella. Puna- ja valkoapilan sekä sinimailasen eri lajikkeet eivät poikenneet toisistaan merkitsevästi, joten tulokset on käsitelty eri kasvilajit lajikkeittain yhdistettynä. Helsingissä ja Ruukissa viljakasvustot puitiin, ja tulokset koskevat puitua satoa. Rovaniemellä kaura korjattiin kokoviljasäilörehuna, ja tulokset kuvaavat koko kasvustoa. Rovaniemellä kasvuston kuiva-aine ja typpipitoisuus määritettiin yhdistelmänäytteestä, joten tuloksille ei esitetä tilastollista käsittelyä. Kokeen tuloksia laskettaessa kunkin kolmen koepaikan tulokset käsiteltiin erikseen. Koemallina käytettiin epätäydellisten lohkojen $\alpha$-mallia, jossa oli 18 koekäsittelyä, 3 toistoa ja 3 lohkoa (Seeger ja Kjeller 1988). Tilastollisena käsittelynä tuloksille tehtiin sekamallien varianssianalyysi SAS-ohjelmiston MIXED-proseduurilla.
\end{abstract}




\section{Tulokset ja tulosten tarkastelu}

Tutkimushankkeen kolmen ensimmäisen vuoden tulokset on raportoitu aikaisemmin eri julkaisussa sekä maaperän typen (Isolahti ym. 2001) että palkokasvien satoisuuden (Nissinen ym. 2001) osalta, joten tässä artikkelissa esitellään tulokset vain nurmipalkokasvien jälkivaikutuksesta maan mineraalityppivaroihin ja kasvustojen lopettamista seuraavan vuoden satoon.

Taulukko 1. Maan mineraalityppimäärä 0 - 100 cm:n syvyydessä syksyllä 2001 ja keväällä 2002, sekä typpimäärän muutos talven aikana Helsingissä, Ruukissa ja Rovaniemellä. Rovaniemellä typpipitoisuus määritetty $0-66$ cm syvyydestä. Koetekijöiden tilastollinen merkitsevyys: $*=\mathrm{P}<0,05, * *=\mathrm{P}<0,01, * * *=\mathrm{P}<0,001,0=\mathrm{P}<0,1$. Tasokeskiarvot, joiden yläindeksissä ei ole yhteistä kirjainta, eroavat parittaisen vertailun mukaan merkitsevästi $10 \%$ riskitasolla. Koekäsittelyt: $1=$ puna-apila, $2=$ puna-apilan ja nurminadan seos, $3=$ sinimailanen, $4=$ sinimailasen ja nurminadan seos, $5=$ valkoapila, $6=$ valkoapilan ja nurminadan seos, $7=$ vuohenherne, $8=$ vuohenherneen ja nurminadan seos, $9=$ keltamaite, $10=$ keltamaitteen ja nurminadan seos, $11=$ nurminata ilman $\mathrm{N}$ lannoitusta, 12 = nurminata N-lannoitettuna.

\begin{tabular}{|c|c|c|c|c|c|c|c|c|c|}
\hline \multirow[b]{2}{*}{ käsittely } & \multicolumn{3}{|c|}{ Helsinki } & \multicolumn{3}{|c|}{ Ruukki } & \multicolumn{3}{|c|}{ Rovaniemi } \\
\hline & $\begin{array}{l}\text { syksy } \\
2001\end{array}$ & $\begin{array}{l}\text { kevät } \\
2002\end{array}$ & muutos & $\begin{array}{l}\text { syksy } \\
2001\end{array}$ & $\begin{array}{l}\text { kevät } \\
2002\end{array}$ & muutos & $\begin{array}{l}\text { syksy } \\
2001\end{array}$ & $\begin{array}{l}\text { kevät } \\
2002\end{array}$ & muutos \\
\hline 1 & $64,7^{\mathrm{ab}}$ & $79,9^{\mathrm{ab}}$ & $-25,4^{b c}$ & $54,1^{\mathrm{ab}}$ & $57,8^{\mathrm{ab}}$ & $-3,9$ & 24,8 & $38,2^{\mathrm{ab}}$ & $-14,3$ \\
\hline 2 & $54,0^{\mathrm{b}}$ & $79,1^{\mathrm{b}}$ & $-23,6^{b c}$ & $44,7^{\mathrm{b}}$ & $51,9^{\mathrm{ab}}$ & $-7,4$ & 21,2 & $33,7^{\mathrm{b}}$ & $-12,8$ \\
\hline 3 & $66,5^{\mathrm{ab}}$ & $106,7^{\mathrm{a}}$ & $-41,6^{\mathrm{c}}$ & $51,8^{\mathrm{ab}}$ & $52,6^{\mathrm{ab}}$ & $-0,6$ & 20,2 & $40,5^{\mathrm{ab}}$ & $-20,2$ \\
\hline 4 & $66,6^{\mathrm{ab}}$ & $91,1^{\mathrm{ab}}$ & $-24,9^{\mathrm{bc}}$ & $47,3^{\mathrm{ab}}$ & $53,9^{\mathrm{ab}}$ & $-6,4$ & 23,0 & $36,3^{a b}$ & $-13,5$ \\
\hline 5 & $61,1^{\mathrm{ab}}$ & $84,5^{\mathrm{ab}}$ & $-20,9^{a b c}$ & $51,8^{\mathrm{ab}}$ & $65,7^{\mathrm{a}}$ & $-13,9$ & 23,6 & $52,0^{\mathrm{a}}$ & $-28,4$ \\
\hline 6 & $67,3^{\mathrm{ab}}$ & $82,9^{\mathrm{ab}}$ & $-12,7^{\mathrm{abc}}$ & $59,7^{\mathrm{a}}$ & $59,0^{\text {ab }}$ & 0,8 & 26,0 & $49,8^{\mathrm{ab}}$ & $-24,1$ \\
\hline 7 & $90,1^{\mathrm{a}}$ & $74,6^{\mathrm{b}}$ & $17,1^{\mathrm{a}}$ & $36,4^{\mathrm{b}}$ & $46,5^{\mathrm{b}}$ & $-10,0$ & 21,6 & $46,2^{\mathrm{ab}}$ & $-23,9$ \\
\hline 8 & $82,4^{\mathrm{ab}}$ & $82,2^{\mathrm{ab}}$ & $3,0^{\mathrm{ab}}$ & $42,6^{\mathrm{b}}$ & $48,0^{\mathrm{ab}}$ & $-5,2$ & 22,7 & $39,7^{\mathrm{ab}}$ & $-15,9$ \\
\hline 9 & $42,6^{\mathrm{b}}$ & $73,5^{\mathrm{b}}$ & $-30,0^{b c}$ & $42,1^{\mathrm{b}}$ & $49,6^{\mathrm{ab}}$ & $-7,6$ & 18,9 & $48,0^{\mathrm{ab}}$ & $-29,1$ \\
\hline 10 & $57,2^{\mathrm{ab}}$ & $104,1^{\mathrm{ab}}$ & $-45,0^{\mathrm{c}}$ & $42,6^{\mathrm{b}}$ & $45,1^{\mathrm{b}}$ & $-2,7$ & 19,0 & $38,1^{\mathrm{ab}}$ & $-19,0$ \\
\hline 11 & $51,9^{\mathrm{ab}}$ & $70,3^{\mathrm{b}}$ & $-17,3^{\mathrm{abc}}$ & $41,7^{\mathrm{b}}$ & $55,2^{\mathrm{ab}}$ & $-13,7$ & 24,8 & $37,0^{\mathrm{ab}}$ & $-11,3$ \\
\hline 12 & $43,0^{\mathrm{b}}$ & $73,0^{\mathrm{b}}$ & $-29,9^{b c}$ & $51,2^{\mathrm{ab}}$ & $63,2^{\mathrm{ab}}$ & $-12,2$ & 21,0 & $31,4^{b}$ & $-9,7$ \\
\hline $\begin{array}{l}\text { keskiarvo } \\
\text { tilastollinen }\end{array}$ & 62,2 & 83,5 & $-20,9$ & 47,2 & 54,0 & $-6,9$ & 22,2 & 40,9 & $-18,5$ \\
\hline merkitsevyys & $*$ & $* *$ & $* *$ & $* *$ & $* *$ & & & $*$ & \\
\hline
\end{tabular}

\section{Maan mineraalityppimäärä}

Maaperästä syksyllä mitattu mineraalityppipitoisuus kertoo siitä, paljonko maassa on huuhtoutumiselle altista typpeä kasvukauden päätyttyä. Keski-Ruotsissa tehdyssä kenttäkokeessa syksyllä määritettyjen maan mineraalityppimäärien on todettu heijastavan seuraavana talvena huuhtoutuvia nitraattityppimääriä (Bergström ja Brink 1986). Huuhtoutumisessa on kyse nimenomaan nitraattitypestä, koska se on liukoisena maanesteessä ja liikkuu helposti maaveden mukana. Orgaanisesta aineksesta vapautuva ammoniumtyppi voi puolestaan olla jonkin aikaa suojassa huuhtoutumiselta pidättyessään sopivissa olosuhteissa kationinvaihtopaikoille. Viljelymaissa ammoniumtyppeä on kuitenkin varsin vähän, sillä ammoniumtyppi pyrkii hapettumaan nitraatiksi nitrifikaatiobakteerien toiminnan seurauksena. (Heinonen ym. 1992).

Viikissä maan mineraalityppipitoisuus oli korkein syksyllä 2001 vuohenherneen jälkeen (taulukko 1). Puhtaana viljelty vuohenherne poikkesi tilastollisesti merkitsevästi puna-apilan ja nurminadan seoksesta, keltamaitteesta ja lannoitetusta nurminadasta. Seuraavana keväänä maan mineraalityppipitoisuudet olivat kohonneet kaikkien muiden kasvien jälkeen vuohenhernettä lukuun ottamatta. Mineraalitypen määrä oli lisääntynyt maassa selvästi myös syvemmissä näytteenottokerroksissa, 33-66 $\mathrm{cm}$ ja 66-100 cm. (tuloksia ei ole esitetty maakerroksittain). Vuohenherneen jälkeen maassa syksyllä ollut korkea mineraalityppimäärä oli talven aikana vähentynyt. Suurin vähennys oli kun vuohenhernettä oli viljelty puhtaana. Viikissä maan typpimäärät nousivat talvenaikana keskimäärin $20,9 \mathrm{~kg} \mathrm{ha}^{-1}$.

Ruukissa maan mineraalitypen määrä oli korkein valkoapilan ja nurminadan seoksissa syksyllä 2001. Seuraavana keväänä maan mineraalitypen määrä oli lisääntynyt lähes kaikissa koekäsittelyissä, ainoastaan valkoapilan ja nurminadan seoksessa oli mineraalitypen määrä hieman laskenut talven aikana. Korkeimmat mineraalityppimäärät olivat keväällä puhtaan valkoapilan ja valkoapilanur- 
minataseoksen jälkeen. Ruukissa mineraalitypen määrä oli lisääntynyt eniten ylimmässä $(0-33 \mathrm{~cm}) \mathrm{ja}$ alimmassa $(66-100 \mathrm{~cm})$ näytteenottosyvyydessä. Muokkauskerroksen alapuolella $(33-66 \mathrm{~cm})$ ei maan mineraalitypen määrä muuttunut syksyn ja kevään näytteenottojen välillä. Mineraalitypen määrä Ruukissa oli alhaisempi kuin Viikissä.

Rovaniemellä maan mineraalityppimäärät syksyllä olivat selvästi matalimmat eri koepaikoista. Yhtenä selityksenä tähän on se, Rovaniemen tulokset kuvaavat mineraalityppimäärää hehtaarilla 66 cm:n syvyyteen ja Viikissä sekä Ruukissa metrin syvyyteen saakka. Syksyllä ei Rovaniemellä ollut tilastollisesti merkitseviä eroja eri koejäsenten välillä maan mineraalintypen määrässä. Kevään näytteenottoon mennessä mineraalitypen määrä maassa lisääntyi sekä ylimmässä että alimmassa näytteenottokerroksessa kaikilla koekäsittelyillä. Eniten mineraalityppeä oli valkoapilan jälkeen.

Syy mineraalityppipitoisuuden lisääntymiseen talven aikana löytyy maan orgaanisesta aineksesta vapautuneesta typestä. Se, että myös Suomen kaltaisissa ilmasto-olosuhteissa mineralisoituu typpeä talvikauden aikana, on aiemmin todettu Sippolan ja Ylärannan (1985) ja Bergströmin ja Brinkin (1986) tutkimuksissa. Talvikauden aikana tapahtuneen orgaanisen typen mineralisoitumisen seurauksena maan mineraalityppivarat lisääntyivät em. tutkimuksissa n. 2 - $20 \mathrm{~kg} \mathrm{ha}^{-1}$, mikä vastaa myös Legsil-projektiin kuuluneissa kenttäkokeissa havaittua mineraalitypen määrän lisäystä. Maan mineraalityppimäärän vähentyminen etelästä pohjoiseen siirryttäessä on selitettävissä palkokasvien menestymisen heikentymisenä esim. suurempien talvituhojen vuoksi. Maan lämpötilalla on myös ratkaiseva merkitys palkokasvien typensidonnan tehokkuuteen (Lindström 1983). Pohjois-Suomessa maan lämpötilat ovat alempia, mikä näkyy maan mineraalityppimäärän pienenemisenä pohjoisemmilla koepaikoilla.

\section{Palkokasvien vaikutus viljan satoon}

Taulukko 2. Puidun viljan sato 15 \% kosteudessa Helsingissä ja Ruukissa. Rovaniemellä sato korjattu kokoviljana. Helsingissä ja Ruukissa typpisato ja sadon typpipitoisuus määritetty puidusta sadosta ja Rovaniemellä kokoviljana korjatusta sadosta. Koetekijöiden tilastollinen merkitsevyys: $*=p<0,05, * *=p<0,01, * * *=p<0,001,0=$ $\mathrm{p}<0,1 \mathrm{~ns}=$ ei merkitsevä $(\mathrm{p} \geq 0,1)$. Tasokeskiarvot, joiden yläindeksissä ei ole yhteistä kirjainta, eroavat parittaisen vertailun mukaan merkitsevästi $5 \%$ riskitasolla. Koekäsittelyt on selitetty taulukossa 1 .

\begin{tabular}{|c|c|c|c|c|c|c|c|c|c|}
\hline \multirow[b]{2}{*}{ käsittely } & \multicolumn{3}{|c|}{$\begin{array}{l}\text { Helsinki } \\
\text { puitu vehnä }\end{array}$} & \multicolumn{3}{|c|}{$\begin{array}{c}\text { Ruukki } \\
\text { puitu kaura }\end{array}$} & \multicolumn{3}{|c|}{$\begin{array}{c}\text { Rovaniemi } \\
\text { kokoviljana korjattu kaura }\end{array}$} \\
\hline & $\begin{array}{l}\text { Sato } \\
\mathrm{kg} \mathrm{ha}^{-1}\end{array}$ & $\begin{array}{l}\mathrm{N} \text { sato } \\
\mathrm{kg} \mathrm{N} \mathrm{ha}^{-1}\end{array}$ & $\begin{array}{l}\mathrm{N} \\
\mathrm{g} \mathrm{kg}^{-1} \mathrm{ka}\end{array}$ & $\begin{array}{l}\text { Sato } \\
\mathrm{kg} \mathrm{ha}^{-1}\end{array}$ & $\begin{array}{l}\mathrm{N} \text { sato } \\
\mathrm{kg} \mathrm{N} \mathrm{ha}^{-1}\end{array}$ & $\begin{array}{l}\mathrm{N} \\
\mathrm{g} \mathrm{kg}^{-1} \mathrm{ka}\end{array}$ & $\begin{array}{l}\text { Sato } \\
\mathrm{kg} \mathrm{ka} \mathrm{ha}^{-1}\end{array}$ & $\begin{array}{l}\mathrm{N} \text { sato } \\
\mathrm{kg} \mathrm{N} \mathrm{ha}^{-1}\end{array}$ & $\begin{array}{l}\mathrm{N} \\
\mathrm{g} \mathrm{kg}^{-1} \mathrm{ka}\end{array}$ \\
\hline 1 & 4028 & 81 & $23,8^{\mathrm{c}}$ & $3338^{\mathrm{abc}}$ & $75^{\mathrm{ab}}$ & $22,5^{\mathrm{ab}}$ & $5119^{\mathrm{ab}}$ & 59 & 11,6 \\
\hline 2 & 3802 & 74 & $23,0^{\mathrm{c}}$ & $3073^{c}$ & $67^{\mathrm{b}}$ & $21,9^{\mathrm{bc}}$ & $4704^{b}$ & 47 & 9,9 \\
\hline 3 & 3740 & 77 & $24,1^{b c}$ & $3353^{\mathrm{abc}}$ & $76^{\mathrm{ab}}$ & $22,5^{\mathrm{ab}}$ & $5273^{\mathrm{ab}}$ & 62 & 11,8 \\
\hline 4 & 4091 & 82 & $23,7^{\mathrm{c}}$ & $3181^{b c}$ & $72^{\mathrm{bc}}$ & $22,5^{\mathrm{ab}}$ & $4748^{\mathrm{b}}$ & 50 & 10,5 \\
\hline 5 & 3439 & 72 & $24,6^{\mathrm{a}}$ & $3611^{\mathrm{a}}$ & $84^{\mathrm{a}}$ & $23,2^{\mathrm{a}}$ & $5589^{\mathrm{a}}$ & 70 & 12,5 \\
\hline 6 & 3991 & 82 & $24,3^{\mathrm{a}}$ & $3557^{\mathrm{ab}}$ & $83^{\mathrm{a}}$ & $23,3^{\mathrm{a}}$ & $5378^{\mathrm{ab}}$ & 67 & 12,5 \\
\hline 7 & 3247 & 72 & $26,0^{\mathrm{a}}$ & $3028^{\mathrm{c}}$ & $69^{b c}$ & $22,8^{\mathrm{ab}}$ & $5335^{\mathrm{ab}}$ & 74 & 13,6 \\
\hline 8 & 3851 & 83 & $25,7^{\mathrm{ab}}$ & $3182^{\mathrm{abc}}$ & $72^{\mathrm{bc}}$ & $22,7^{\mathrm{ab}}$ & $5091^{\mathrm{ab}}$ & 66 & 13,0 \\
\hline 9 & 3372 & 69 & $24,0^{\mathrm{bc}}$ & $3110^{c}$ & $69^{b c}$ & $22,1^{b c}$ & $5136^{\mathrm{ab}}$ & 70 & 13,6 \\
\hline 10 & 3979 & 80 & $23,8^{\mathrm{c}}$ & $2976^{\mathrm{c}}$ & $65^{b c}$ & $21,8^{\mathrm{bc}}$ & $5137^{\mathrm{ab}}$ & 59 & 11,5 \\
\hline 11 & 4001 & 78 & $22,8^{\mathrm{c}}$ & $2796^{\mathrm{c}}$ & $60^{c}$ & $21,5^{\mathrm{c}}$ & $5815^{\mathrm{a}}$ & 70 & 12,2 \\
\hline 12 & 3340 & 63 & $22,1^{\mathrm{c}}$ & $3061^{\mathrm{c}}$ & $67^{\mathrm{bc}}$ & $21,9^{\mathrm{bc}}$ & $4916^{\mathrm{ab}}$ & 60 & 12,0 \\
\hline keskiarvo & 3740 & 76,1 & 24,0 & 3241 & 71,6 & 22,4 & 5187 & 62,8 & 12,1 \\
\hline merkitsevyys & & & $* * *$ & $* * *$ & $* * *$ & $* * *$ & $* * *$ & & \\
\hline
\end{tabular}

Viikissä viljelty vehnä kärsi kuivuudesta vuonna 2002, ja kasvusto oli hyvin epätasaista (taulukko 2). Suuresta hajonnasta johtuen käsittelyjen välillä ei ollut tilastollisesti merkitseviä eroja. Korkeimmat typpipitoisuudet kasvustossa olivat kun esikasvina oli viljelty vuohenhernettä tai valkoapilaa joko puhtaana tai seoksena. Matalimmat typpipitoisuudet olivat puhtaan nurminadan jälkeen. Vehnän hehtolitrapainoon tai tuhannen siemen painoihin ei esikasvilla ollut vaikutusta (tuloksia ei esitetty). 
Ruukissa kauran sato oli korkein, kun esikasvina oli valkoapila joko puhtaana tai seoksena. Ruukissa puhtaiden palkokasvien viljely lisäsi kauran satoa verrattuna palkokasvien viljelyyn seoksena nurminadan kanssa lukuun ottamatta vuohenhernettä. Heikoin esikasvivaikutus oli keltamaitteella ja puhtaalla nurminadalla. Kaikkein pienin kauran sato oli, kun esikasvina oli lannoittamaton nurminata. Myös typpisato oli korkein kun esikasvina oli valkoapila, samoin kauran typpipitoisuus. Kaurallakaan ei esikasvilla havaittu vaikutusta hehtolitrapainoon tai tuhannen siemen painoihin.

Rovaniemellä kuva-ainesato oli poikkeuksellisesti korkein lannoittamattoman nurminadan jälkeen. Palkokasveista korkein kuiva-ainesato oli valkoapilan jälkeen. Myös Rovaniemellä kauran sadot olivat korkeampia puhtaiden palkokasvinurmien kuin seosnurmien jälkeen. Yhdistelmänäytteissä korkeimmat typpipitoisuudet olivat vuohenherneen ja keltamaitteen jälkeen. Koejäsenittäin tehdyn näytteenoton vuoksi tuloksista ei kuitenkaan pysty tekemään pidemmälle meneviä johtopäätöksiä.

\section{Johtopäätökset}

Eri palkokasvien esikasviarvo riippui täysin niiden menestymisestä koepaikalla. Helsingissä palkokasvit menestyivät parhaiten. Varsinkin talvehtimiskyvyltään heikommat kasvilajit sinimailanen, vuohenherne ja keltamaite menestyivät Etelä-Suomessa suhteellisesti paremmin puna- ja valkoapilaan verrattuina kuin pohjoisempana. Ruukissa valkoapila menestyi erinomaisesti, joten se oli paras esikasvi sekä puhtaana että seoksena viljeltynä. Puna-apila ei eronnut merkitsevästi valkoapilasta. Vuohenherne ja varsinkin keltamaite olivat esikasveina selvästi apiloita huonompia. Ruukissa puhtaiden palkokasvien esikasvivaikutus oli parempi kuin seosnurmien tai puhtaan nurminadan.

Maan mineraalitypen määrä nousi kaikilla koepaikoilla syksystä kevääseen. Ainoastaan Viikissä vuohenherneellä mineraalitypen määrä maassa väheni selvästi talven aikana, mikä on merkki nitraatin huuhtoutumisesta. Myös muissa käsittelyissä on todennäköisesti tapahtunut typen huuhtoutumista eri koepaikoilla, mutta maasta mineralisoituneen typen määrä on ollut huuhtoutumista suurempaa. Varsinkin karkeammilla maalajeilla mineraalityppeä on kulkeutunut syvemmälle, mikä koesarjassa on todettu jo aikaisemminkin (Isolahti ym. 2001). Poikkeuksena aikaisemmin raportoituun myös Viikin hienojakoisella savimaalla oli havaittavissa aikaisempaa selvemmin typen kulkeutuminen maassa syvemmälle. Syynä tähän oli maan kyntäminen syksyllä, mikä kiihdytti typen mineralisoitumista. Palkokasveja sisältävien nurmien lopettamisen yhteydessä pitäisi pyrkiä estämään typen voimakas mineralisoituminen syksyllä, koska silloin riskit mineraalitypen hävikkeihin lisääntyvät. Yhtenä keinona typen mineralisoitumisen vähentämiseen on muokkauksen myöhästyttäminen (Känkänen ym. 1998) .

\section{Kirjallisuus}

Adams, J. A. \& Pattison, J. M. 1985. Nitrate leaching losses under a legume-based crop rotation in central Cantebury, New Zealand. New Zealand J. Agric. Res. 28: 101 - 107.

Bergström, L. 1986. Distribution and temporal changes of mineral nitrogen in soils supporting annual and perennial crops. Swedish J. Agric. Res. 16: 105 - 112.

Bergström, L. \& Brink, N. 1986. Effects of differentiated applications of fertilizer N on leaching losses and distribution of inorganic $\mathrm{N}$ in the soil. Plant and Soil 93: 333-345.

Heinonen, R., Hartikainen, H., Aura, E., Jaakkola, A. \& Kemppainen, E. 1992. Maa, viljely ja ympäristö. Helsinki. 334 p.

Isolahti, M., Huuskonen, A., Tuori, M. \& Nissinen, O. 2001. Nurmipalkokasvien vaikutus maan mineraalityppivaroihin. In: toim. Mikko Tuori, Mari Topi-Hulmi, Eeva Saarisalo. Nurmipalkokasvien tuotanto ja käyttömahdollisuudet: Professori Liisa Syrjälä-Qvistin juhlaseminaari 1.11.2001. SNY:n julkaisu 16: 24-32.

Känkänen, H., Kangas, A., Mela, T., Nikunen, U., Tuuri, H. \& Vuorinen, M. 1998. Timing incorporation of different green manure crops to minimize the risk of nitrogen leaching. Agric. Food Sci. Fin. 7: 553-567.

Lindström, K. 1983. Biologinen typensidonta palkokasvien viljelyssä. Suomen Akatemian sopimustutkimuksen no. 383 loppuraportti. p. 265-280.

Low, A. J. 1973. Nitrate and ammonium nitrogen concentration in water draining through soil monoliths in lysimeters cropped with grass or clover or uncropped. J. Sci. Food and Agric. 24: 1489 - 1495.

Nissinen, O., Tuori, M., Isolahti, M., Hakkola, H., Heikkilä, R. \& Syrjälä-Qvist, L. 2001. Nurmipalkokasvien satoisuus. In: toim. Mikko Tuori, Mari Topi-Hulmi, Eeva Saarisalo. Nurmipalkokasvien tuotanto ja käyttömahdollisuudet: Professori Liisa Syrjälä-Qvistin juhlaseminaari 1.11.2001. SNY:n julkaisu 16: 14-23.

Robbins, C. W. \& Carter, D. L. 1980. Nitrate-nitrogen leached below the root zone during and following alfalfa. J. Env. Quality 9: $447-450$.

Seeger, P. \& Kjeller, M. 1988. Efficiency of generalized lattices in swedish variety trials. Swedish J. Agric. Res. 18: 155-159.

Sippola, J. \& Yläranta, T. 1985. Mineral nitrogen reserves in soil and nitrogen fertilization of barley. Annales Agriculturae Fenniae 24: 117-124. 